\title{
The Science Behind Powerful Questioning: A Systemic Questioning Framework for Coach Educators and Practitioners
}

\author{
Laura L. Hauser \\ California, USA
}

\begin{abstract}
At the heart of the coaching process is the core competency of questioning, often referred to as powerful questioning. Coach educators and trainers diligently teach students the importance of asking questions (versus giving advice) during coaching sessions and teach them to structure questions appropriately (such as using open versus closed-ended questions). Still, coaching students struggle with knowing what questions to ask and when during their work with clients. Although many students search for a list of so-called magic coaching questions, I contend that coaches instead need a framework of questioning to use when coaching a client. A questioning framework could help educators teach the science of questioning as a means for developing coaches' professional judgment, thereby helping coaches make better-informed choices about what types of questions to ask clients during coaching sessions. This paper presents an evidence-based conceptual framework called the Systemic Questioning Framework. Application of the framework during a coaching conversation may increase the coach's confidence and competence when making decisions regarding how to shape questions in the moment in response to the client, enabling better coaching outcomes.
\end{abstract}

Keywords: powerful questioning, dialogue, systems thinking, executive coaching, team coaching

\section{Introduction}

In my work as a graduate-level coach educator, assessor, and supervisor for two accredited programs, I teach a combination of performance skills, theoretical knowledge, and ICF core competencies. Despite the skill and knowledge students gain through this education process, they often worry about not knowing what questions to ask during a coaching session. Sometimes they do not realize that asking simple questions about the context of the presenting situation can serve as inputs for crafting a powerful question which in turn may have the potential to create a positive shift in the client.

During one recent individual supervision session, a student who works as a director of talent management for a national distribution company lamented about how he got stuck when coaching a client. I already had listened to a 
recording of the coaching session he conducted before we met for supervision and prepared some notes for our supervision conversation. I noticed, for example, that the rhythm of the coaching conversation was broken when the student asked his client a long, meandering question. His client responded by saying she was confused. Here is how my coaching supervision conversation with my student unfolded about this break of rhythm. (Note my use reflective questions to help increase his self-awareness about his decision-making process for asking questions):

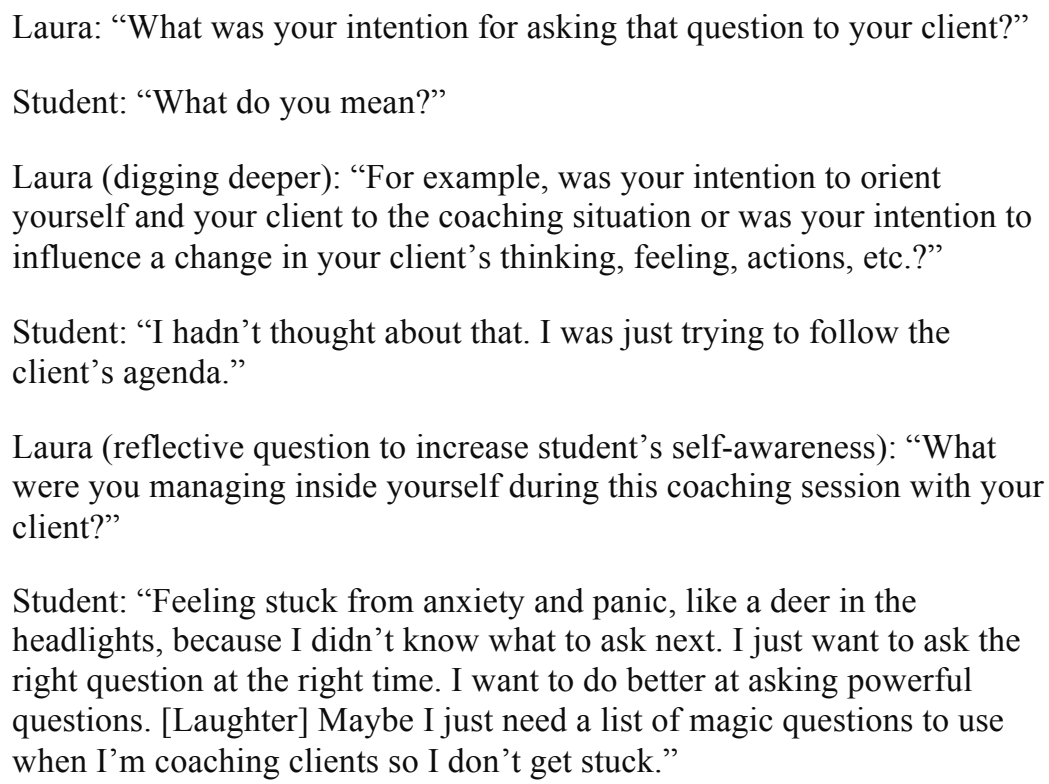

Although I applaud the student's desire to effectively coach his client, relying on a so-called magic list of questions applicable to any coaching situation is misguided, because coaching is a dynamic process that resists prescription (Rogers, 2016). Rather than searching for a magical list of questions, coaches need to understand the science of questioning to guide their decisions about what types of questions to ask and when. In doing so, they increase their professional judgment. Murphy (2006) defined the concept of professional judgment as using knowledge (e.g., evidence-based models, frameworks and/or theory) to guide and evaluate one's own decisions and actions. By increasing one's professional judgment about the science of questioning, coaches can make informed decisions about how to shape questions that could positively impact the client within the context of the coaching goal and the client's environment. The result can be far fewer 'deerin-the-headlights' coaching moments and far more time being present and effective when working with clients. 
This paper presents an evidence-based framework called the Systemic Questioning Framework (SQF) for use by coach educators, trainers, and practitioners. It categorizes the core competency of questioning into four types of questions: clarifying, meaning making, catalyzing, and mobilizing. The ICF core competency of 'powerful questioning' resides within the catalyzing category of the SQF. It is important to note that other types of questions such as clarifying and meaning-making questions serve as inputs to making decisions about when and how to as a powerful question. The balance of this paper outlines the theoretical underpinnings of the framework, discusses how it may be applied, and considers its implications for practice.

\section{Questioning as a coaching competency}

Coaching is an emerging and cross-disciplinary occupation (Gray, 2011) practiced by professional coaches, managers, consultants, human resource professionals, and corporate leaders (Ruane, 2013). The diverse demographics of its practitioners position coaching in an ambiguous status as a field of practice. As part of the move to professionalize and standardize the field, different organizations and researchers have identified a number of core competencies that underlie effective coaching. Core coaching competencies refer to the capabilities, unique skills, approaches, and behaviors that coaching professionals need to employ to effectively assist clients in pursuing their goals (Maltbia, Marsick, \& Ghosh, 2014). Various core competency definitions have been outlined for coaches, such as the International Coach Federation's 11 core coaching competencies (ICF, 2017), and the Worldwide Association of Business Coaches's 15 competencies (WABC, 2017).

It is generally accepted that during a coaching conversation, coaches respond to their clients with both statements and questions. For example, coaches practice direct communication using a coaching approach to share observations, intuitions, thoughts, or feelings, without attachment to being right (ICF, 2017). Importantly, although coaching behaviors include making statements, coaching is primarily an inquiry-based practice. Cox (2013) claimed that questioning is the key competency within the coaching context, but noted that no specific theory of questioning exists for guiding coaching professionals in enacting this critical capability.

Although the ICF provides a definition and behavioral markers of the core competency called powerful questioning (one specific type of questioning), the coaching literature lacks a science of asking coaching questions, in general. What is needed in the coaching field and practice are 
coaching specific theoretical frameworks to increase professional judgment that can inform coaches' decisions about what types of questions to ask (and when to ask them) during the coaching conversation.

\section{Models of questioning}

\section{Empirical coaching framework}

I conducted an empirical research study about coaching teams to identify the behaviors coaches use when interacting with a team and to identify what influenced the coaches' choices of behaviors (Hauser, 2014). The research culminated in a new team coaching framework called Shape-Shifting.

According to the Shape-Shifting framework, coaches' role behaviors vary along two independent continuums: (a) directive, the extent to which the coach offers statements, provides education models, and makes suggestions, and (b) dialogic, the extent to which the coach uses a client-centered, relational stance of inquiring and exploring while interacting with the team. Importantly, this continuum breaks an ideological barrier in coaching by finding that coaches do at times exhibit directive behaviors such as suggesting and educating.

The concept that coaches vary from more directive (task-oriented, telloriented) to less directive (process-oriented; ask-oriented) role behaviors supports other literature about the roles and functions of coaching (Clutterbuck, 2007; Glaser \& Strauss, 1967; Hackman \& Wageman, 2005; Hamlin et al., 2007; Huffington, 2007; Ives, 2008; Lippitt \& Lippit, 1986). My research further indicated that coaches spend the majority of their time on the nondirective end of the continuum, meaning they more often use inquiry-based behaviors and less often uses telling-types of behaviors.

The concept of the dialogic stance is consistent with Stein's (2008) work on conversational identities and with Bushe and Marshak (2009) and Marshak and Grant (2008), who describe discursive, conversational approaches as a means for creating change. When coaches use dialogic behaviors, they engage in two-way conversations with clients and serve as partners who help clients deeply explore the current situation and then shift toward new ways of thinking and behaving (Brunning, 2006; Gottlieb, 1997; Stein, 2008).

Combining the two continuums, I classified four roles available to the coach depending on client need to support an intended outcome: advisor (high directive/low dialogic); educator (high directive/high dialogic); catalyzer (low 
directive/ high dialogic); and assimilator (low directive/low dialogic). These role behaviors vary over time and are located at different points along directive and dialogic continuums. I used the metaphor of shape-shifting to illustrate that coaches fluidly and intentionally shift their "shape" (i.e., their roles and behaviors) depending on the situation in the moment and over time.

I realized that these role categorizations help inform a science of questioning for coaches. For example, if coaches take on an advisor role, the nature and intent of their questions would differ than when they play a catalyzing role. By reflecting on the function of each role in a coaching relationship, coaches can generate questions that honor the intent of the role and the needs of the client in that moment.

The dialogic continuum from the Shape-Shifting Framework also is consistent with a coaching approach to questioning because it assumes a relational, client-centered stance. However, the directive continuum and its focus on making statements likely would not be included in a questioning framework because the very nature of questioning is based on inquiry. Thus, although coaches use both statements and questions during a coaching session, this paper focuses on creating a framework to elucidate the science behind the core competency of questioning.

The questioning framework presented in this paper builds upon the dialogic continuum of the Shape-Shifting Framework as well as a questioning model drawn from the family systems therapy literature. The next two sections describe this family systems model and how it has been adapted for use in organizational settings.

\section{Interventive Interviewing Framework}

Tomm's $(1987,1988)$ Intervening Interview model suggests that therapists use different types of questions for different functions, from those that orient the therapist to the client's situation and experiences to those that provoke therapeutic change. He further observed that questions vary in the extent to which they indicate a judgmental versus neutral or accepting attitude from the therapist. Tomm located therapeutic questions on two dimensions: (a) intention, which indicates whether the therapist's question aims to gather information about the client's situation (orienting) or help the client move toward a certain outcome (influencing) and (b) assumption, which indicates whether the therapist's question is meant to help clients see how they have 
erred or how they ought to behave (lineal) or whether the therapist's question invites clients to solve their own problem (circular).

The two dimensions yield four types of questions:

1. Lineal questions (orienting intent with lineal assumption): Investigate by asking questions about who, what, when, where, how long, and why of the presenting issue, thus eliciting information from the client to build both the therapist's and the client's understanding of the client's situation.

2. Circular questions (orienting intent with circular assumption): Invite the client to share information about the situation and to clarify relevant context and relationships, enabling the therapist and client to make new discoveries. For example, these discoveries may include recurrent patterns that connect persons, objects, actions, perceptions, ideas, feelings, events, and beliefs within a context.

3. Strategic questions (influencing intent with lineal assumption): Influence change in the client by asking leading questions (e.g., "What would happen if you come home at 6:00 every night for a week?"). Strategic questions are intended to be corrective and can help shift a stuck system.

4. Reflexive questions (influencing intent with circular assumption): Draw upon the client's own knowledge, competencies, problem-solving, and idea-generating resources by focusing clients' awareness on their own behaviors and influencing desired behavior changes.

Some elements of this model align well within the context of coaching. For example, circular types of questions have a posture of acceptance, dialogically co-creating meaning, and engaging in conversational partnerships with clients - all of which are consistent with coaching approaches. Reflexive types of questions most closely resemble the coaching competency of powerful questioning (the type of questioning cited in ICF's [2017] list of core competencies) in that they catalyze change by helping clients construct their own goal-oriented solutions.

Lineal assumptions do not transfer as well to a coaching context. From a coaching perspective, clients do not need coaches to correct them or pressure them to do what the coach thinks is best. At the same time, coaches may sparingly use lineal questions to orient to the client's situation and use strategic questions to help clients get unstuck, yet the stance of the coach would remain 
dialogic (not corrective). In this way, applying Tomm's (1988) Interventive Interviewing model to coaching would require adaptation - particularly related to lineal assumptions. The critical take away from Tomm's framework is that coaches may increase their professional judgment by being aware of their intention about what types of questions they are using and for what effect.

\section{Adaptation of Interventive Interviewing model for use in organizations}

Hornstrup et al. (2012) adapted Tomm's (1988) Interventive Interviewing model for use in organizations. First, they explicitly added the lens of a social constructionist paradigm, which assumes that people create their own sense of reality through their interactions with others and their environments. It follows, according to this paradigm, that multiple realities exist and perceptions of reality can change over time, which is consistent with a coaching approach.

Second, Hornstrup et al. replaced the assumptions dimension with a time dimension of past, present, future. This change meant that all questions asked were circular in nature, but varied in terms of whether they were asking about past choices, present options, or future possibilities. The time dimension is consistent with my practical experience and empirical research that coaching conversations have a natural life cycle. The coaching conversation typically begins with an exploration of the presenting situation that often is linked to a past event or situation. After the coach and client sufficiently understand the content and context of the presenting situation, the coaching conversation shifts toward the future, developing a picture of the future desired state and crafting some actions about that desired future state.

Third, they adapted Tomm's intention dimension: Although they kept the orienting intention, they replaced the term "influencing" with "constructing" to underscore the social constuctionist paradigm. Fourth, question types were phrased to reflect organizational language (e.g., lineal questions became situation-clarifying questions). Fifth, Hornstrup et al. pointed out that within organizational settings, questions should not only focus on oneself, but also on one's context (i.e., the larger system or organization within which the issue is occurring) and one's meta-context (i.e., the relationship between the coach and client). The incorporation of a systemic approach to coaching helps address criticisms that the coaching field often fails to place systemic factors at the core of the coaching process (Brown \& Grant, 2010).

Despite its benefits for elucidating the systemic component and the time dimension to Tomm's (1988) model, Hornstrup et al.'s removal of the circular 
assumption dimension may be problematic for developing a broad science of questioning. This is because coaching is deeply rooted in the concept of a dialogic (partnering with client) stance; Tomm's circular assumption represents this type of client-centered approach. A dialogic stance nurtures the coachclient relationship, fostering an environment characterized by curiosity, openness, and trust, thus enabling the possibilities of co-exploration and cocreation. Thus, I contend that a questioning framework for use in the context of coaching should include this important concept of dialogue.

\section{Creating a Questioning Framework for Coaching}

The frameworks discussed in this paper (Hauser, 2014; Hornstrup et al., 2012; Tomm, 1987) offer insights into the science behind questioning. I applied these insights to the context of coaching to create an expanded conceptual framework called The Systemic Questioning Framework (SQF). Five features distinguish the SQF from the Interventive Interviewing model:

- A time dimension (past, present, future) is superimposed onto the intention continuum

- A dialogic stance continuum replaces the assumptions continuum

- A distinct set of four question types are outlined

- Purposes, effects, and risks of each question type are acknowledged

- Three systemic levels for each question type are identified

My first step was to add time as a context marker in relation to the intention (orienting/influencing) continuum (see horizontal axis in Figure 1 below). Time was added because the coach's intention at the beginning of a coaching session is to orient oneself and the client to the presenting situation, and to events or experiences that occurred in the past that lead to the present situation. Furthermore, an orienting intent helps the coach and client understand the context of the situation such as what meaning the client makes about the situation. Once the coach and client have an understanding of the situation, then the coach's intention shifts toward influencing some sort of change. For example, a change may occur in client's perceptions or beliefs, which in turn may generate new possibilities that lead to a new awareness and mobilizes the client's energy toward the future.

Second, I replaced the assumptions continuum with a dialogic stance (see vertical axis) because a lineal assumption, with its characteristic corrective 
posture and judgmental effect, opposes the client-centered relational approach of coaching. The dialogic stance presented in the framework is characterized by a relational posture taken by the coach that maintains the coach-client relationship and fosters mutual understanding, reflection, learning, and calls to action. The two ends of the dialogic continuum are labeled initiating and reflecting. For example, a coach would use an initiating stance to begin the discovery about the client's situation, then later in the conversation would initiate actions toward a future desired state. A coach would use a reflecting stance to help reveal the clients' deeper thinking and feelings regarding their present situation and future possibilities.

The intersection of the coach's intent (with time markers) and the coach's stance toward the client looks like the visual in Figure 1.

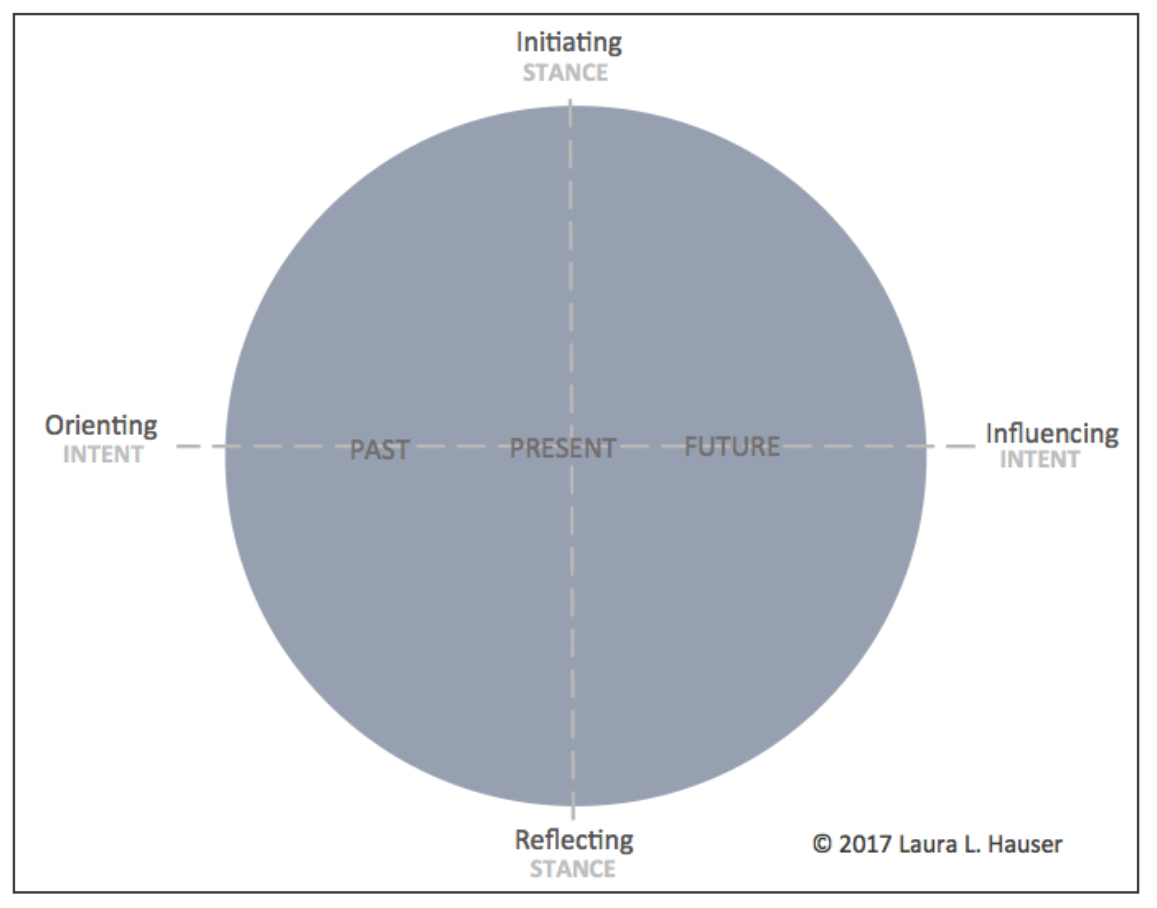

Figure 1. Two Dimensions of the Systematic Questioning Framework

My third step in creating the framework was to label the four types of questions produced by the two dimensions. Each question type was labeled to reflect language that more closely aligns with coaching versus therapeutic traditions. These types are: clarifying (orienting and initiating), meaning making (orienting and reflecting), catalyzing (reflecting and influencing), and 
mobilizing (initiating and influencing). For example, coaches ask clarifying and meaning-making questions to generate understanding for both the client and the coach, which serves as inputs to formulate catalyzing and mobilizing types of questions to effect change and stimulate action.

I found that each type of question was associated with a particular reason for asking, desired result, and potential unwanted consequence. For example, Tomm (1988) emphasized that the actual effect of a question on a client may be different than what was intended. If coaches can anticipate potential

disconnects, they may experience less anxiety, deer-in-the-headlights moments, and more space to consider alternative actions when questions fail to have the desired impact. Understanding the potential risk of different types of questions also is important for identifying potential overuse or adverse impacts of questioning. Therefore, my fourth step in creating the framework was to explicitly identify the purpose, intended effect, and risk for each question type.

Fifth, consistent with Hornstrup et al. (2012), I recognized that each type of question may be posed to any or all three levels of the organizational system: self (the client), contextual (the client's broader system), and meta (alliance between the coach and client). Although sample questions are offered in the next section to elucidate the meaning of each type of question and the different levels of the system, these questions are not meant to be prescriptive nor all inclusive.

\section{Systemic Questioning Framework}

The SQF (see Figure 2) suggests that coaches initiate coaching conversations with the clients in a dialogical way to investigate the presenting situation and help shape a coaching goal for the session. The coach often begins by using clarifying questions to investigate the who, what, when, where, how of the situation.

During this discovery, the coach expands the dialogue by delving into meaning-making questions and digging deeper into reflections related to the client's values and feelings about the situation. The conversation and information gained begins to influence changes in thinking and/or feeling, associated with the use of catalyzing types of questions that test and even challenge the client's perceptions, thinking, and behaviors.

Once a new awareness or learning has occurred, then the coach often initiates a conversation using mobilizing questions that direct energy toward the 
future and help construct actions and learning that move clients toward actualizing their goals. Along the way, the coach considers asking the four types of questions through the lens of the three different systemic levels.

It is important to mention that although the example I just provided may sound like a linear process, it is not. The SQF is a dynamic model such that coaches shift the type of question in response to client needs in the moment.

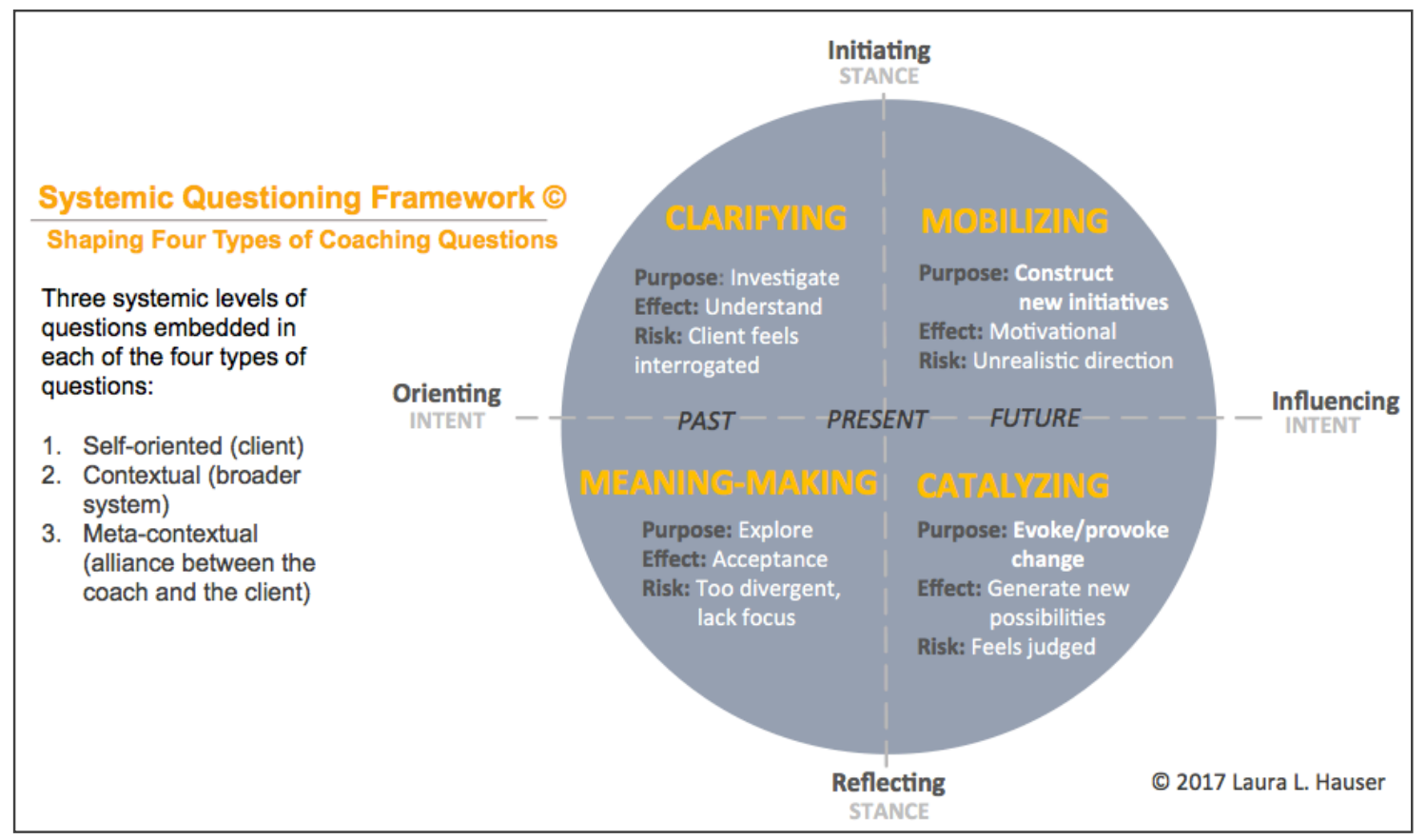

\section{Figure 2: Systemic Questioning Framework}

Let's now delve more deeply into the practical application of the model organized by each of the four types of questions. After a brief discussion of each type of question, sample questions are offered categorized by the three levels of system (self, contextual, and meta).

1. Clarifying questions (orienting intention with initiating stance): The purpose of asking clarifying questions is to help the coach and the client understand the client's current situation and relevant past information related to the situation. Answers to these questions help the coach and the client align their understanding of the situation and build a common ground for the future generative part of the coaching session. The coach's stance during the dialogue tends to be more initiating than 
reflecting. Like a detective, the coach investigates facts such as who, what, when, where, how long, and even why. The intended effect of asking clarifying questions is to build understanding about the presenting situation. Although clarifying questions can help surface information critical to the coaching goals, overuse of clarifying questions can result in the client feeling interrogated.

\begin{tabular}{|l|l|}
\hline System Level & Sample Questions \\
\hline Self-oriented & $\begin{array}{l}\text { What is the focus of our session } \\
\text { today? } \\
\text { How did this situation come about? } \\
\text { How often does this happen? }\end{array}$ \\
\hline Contextual & $\begin{array}{l}\text { Who else is involved? } \\
\text { Whose interests are also at stake? } \\
\text { What else needs to be addressed or } \\
\text { resolved in relation to this situation? }\end{array}$ \\
\hline Meta-contextual & $\begin{array}{l}\text { How would you like me to work with } \\
\text { you during our coaching session } \\
\text { today? }\end{array}$ \\
\hline
\end{tabular}

2. Meaning-making questions (orienting intention with reflecting stance). The purpose of asking meaning-making questions is to explore below the surface of the client's narrative. A meaning-making type of question orients both the coach and the client to what is underneath the situation and to the whole person. The coach's stance is dialogic in nature, like an archeologist digging deeper into the client's values, assumptions, feelings, and thinking to gain insight into the core of the presenting issue. The intended effect on the coach and client is a feeling of acceptance, which cultivates an expanded level of trust and intimacy within the coach-client alliance. The overuse of meaning-making questions, however, can result in a lack of focus for the coaching session and a sense of confusion.

\begin{tabular}{|l|l|}
\hline System Level & Sample Questions \\
\hline Self-oriented & $\begin{array}{l}\text { What makes this so important to you } \\
\text { now? } \\
\text { What is the impact on you? }\end{array}$ \\
\hline Contextual & $\begin{array}{l}\text { What do other people close to this } \\
\text { situation say about it? }\end{array}$ \\
\hline
\end{tabular}




\begin{tabular}{|l|l|}
\hline & What is important to them? \\
\hline Meta-contextual & $\begin{array}{l}\text { What impact is this coaching having } \\
\text { on you and our coaching relationship? }\end{array}$ \\
\hline
\end{tabular}

3. Catalyzing questions (influencing intention with reflecting stance). The purpose of asking catalyzing types of questions is to test clients' beliefs and actions by inviting them to reflect on the thoughts, feelings, and patterns embedded in their narrative for the purpose of evoking or provoking a change. The potential effect of a catalyzing question is to help the client experience a new awareness such as seeing new patterns of beliefs and behaviors. This opens space for the client to generate new possibilities toward his or her future desired goal. Notably, it is the catalyzing type of question that I characterize as a powerful question (consistent with ICF [2017] core competencies) because catalyzing types have the potential to help clients explore beyond their current thinking about the situation, themselves, and their desired outcomes. A possible risk of catalyzing questions is the client feeling judged. Care should be taken to not jeopardize the coach-client alliance. I often say to my students, "The coaching intervention (such as asking a catalyzing question) can only be as strong as the relationship." Furthermore, catalyzing questions should not be disguised as leading questions.

\begin{tabular}{|l|l|}
\hline System Level & Sample Questions \\
\hline Self-oriented & $\begin{array}{l}\text { How do you know that is true? } \\
\text { What is holding you back from making } \\
\text { the change you say you want to make? } \\
\text { What is the benefit to you of making a } \\
\text { change? Risk to you for making a } \\
\text { change? } \\
\text { What do you want instead? What is } \\
\text { your ideal picture of the future? }\end{array}$ \\
\hline Contextual & $\begin{array}{l}\text { If I asked people around you, what } \\
\text { would they hope you would do now? } \\
\text { What possibilities do other people or } \\
\text { groups hope this conversation will } \\
\text { generate for them? } \\
\text { What implications could your decision } \\
\text { to change, or not change, have on } \\
\text { others? }\end{array}$ \\
\hline
\end{tabular}




\begin{tabular}{|l|l|}
\hline $\begin{array}{l}\text { Meta- } \\
\text { contextual }\end{array}$ & $\begin{array}{l}\text { As you reflect on our working } \\
\text { relationship so far today, how is it } \\
\text { going? What is our ideal picture of our } \\
\text { alliance and how we work together? }\end{array}$ \\
\hline
\end{tabular}

4. Mobilizing questions (influencing intention with initiating stance). The purpose of asking mobilizing questions is to initiate a conversation with the client to construct a plan and identify actions, resources, and structures in service of their goal attainment. Furthermore, mobilizing questions help clients claim the learning they experienced during the coaching session by appreciating what is new and different in relation to the client situation compared to the beginning of the coaching session. The effect of mobilizing questions can be motivational in nature, helping clients build commitment to their action plan for achieving their desired goal. A possible risk of mobilizing questions, however, is premature closure on exploration of the desired future direction. For example, designing actions toward the goal can be damaging if actions are crafted toward an unrealistic or unwanted picture of the future.

\begin{tabular}{|l|l|}
\hline System Level & Sample Questions \\
\hline Self-oriented & $\begin{array}{l}\text { How motivated are you to step into your picture } \\
\text { of the future? } \\
\text { What actions might you take to achieve your } \\
\text { goal? } \\
\text { What resources or other supports are available } \\
\text { to you? }\end{array}$ \\
\hline Contextual & $\begin{array}{l}\text { What barriers would get in the way of attaining } \\
\text { your goal? } \\
\text { Who could help you get what you want? }\end{array}$ \\
\hline $\begin{array}{l}\text { Meta- } \\
\text { contextual }\end{array}$ & $\begin{array}{l}\text { What have we accomplished together today that } \\
\text { will be useful to us going forward? } \\
\text { How might we refine our process and celebrate } \\
\text { successes? }\end{array}$ \\
\hline
\end{tabular}

Although the SQF has not yet been empirically tested, I am glad to offer an anecdotal story about its use by continuing the story about the deer-in-theheadlights student I mentioned at the beginning of this article. During our supervision session, I educated him about the SQF. He later sent a follow-up 
email that provided more insights about his challenges and how the SQF helped him overcome them. He acknowledged:

As you know, I've been struggling with this particular client and wondered if I'm not the right coach for this particular client. She seemed to have no real desire to reflect beyond the surface and maybe no real belief in the efficacy of what we were doing. I actually haven't experienced a client like her. This is about me though, so my reflection has been either a) I'm experiencing an uncoachable client or b) It's showing some lack of capability on my part and I'm not sure what the gap is.

He further shared that the SQF revealed a gap in his use of questioning:

\begin{abstract}
The questioning model you've been using with me helped me realize I've been missing one piece of the puzzle - catalyzing questions. I do a good job asking questions about her situation and exploring the more deeply about the situation, then I go straight to designing actions. But that was a problem because she stayed stuck in her story. We never made any real progress.
\end{abstract}

So this time, I got up the courage to ask a few catalyzing questions. For example, she said that she "could be wrong." In the past, I would not have known what to do with that kind of comment. Instead of feeling anxiety about not knowing what to ask next, your model flashed inside my head. I knew it was time for a catalyzing question, so I asked "In what way could you be wrong?" But still there was no shift. So I said, "Can I share an observation? I notice we've traveled down this same path a few times. I'm not feeling particularly helpful to you (smile). I wonder, what could I say now that might make a real difference for you?" I noticed a huge shift in our conversation and in her.

My student's experience while learning and applying the SQF indicates that the framework may indeed hold insights not only about a broad science of questioning but also for developing the specific competency of powerful questioning. It follows that the SQF may help coaches gain critical selfawareness and confidence that helps them refine their craft.

\title{
Three cautions when applying the Systemic Questioning Framework
}

The SQF is proposed as a conceptual framework for use by coach educators and practitioners. When considering the use of the framework, three cautions are worth discussion consideration. First, the framework's focus on questioning does not imply that coaches should only ask questions during coaching conversations. Instead, coaches also need to offers statements and perspectives during the coaching conversation, consistent with the ICF (2017) 
core competency of direct communication. Using this approach, "the coach shares observations, intuitions, comments, thoughts and feelings to serve the client's learning or forward movement" (marker 7.1).

Second, the framework outlines a broad science of questioning that includes the specific core competency of powerful questioning (classified as a catalyzing type of question in the SQF). Accordingly, the SQF suggests that coaches need to be aware and adept with a range of question types. Moreover, the framework's focus on questioning also does not imply that a core competency of powerful questioning is more important than any other coaching core competency. Rather, questioning should be integrated with other core coaching competencies such as trust and intimacy, coaching presence, and direct communication.

Third, the SQF is neither prescriptive nor linear. Instead, it is iterative to support the dynamic nature of the coaching conversation. The framework serves as a mental model that coaches may access in the moment to help navigate the coaching conversation. To effectively and responsively shift the shape of their questions, coaches need to flexibly dance in the moment with the client, moving around the framework as indicated by the client's needs and goals for the coaching conversation.

Last, it is important to emphasize that a client-centered philosophy is embedded within the Intention and Stance dimensions of the model. The coach remains in a state of curiosity during the coaching conversation and views the client as whole and resourceful.

\section{Implications for coach educators and practitioners}

The SQF is intended to help educators develop coaches' professional judgment by enhancing coach awareness of the four types of coaching questions. Each type of question offers potentially different risks and effects for multiple levels of the coaching situation. Rather than a prescribed set of questions, the framework helps ground the coach in the impact they wish to have. When coaches are more connected to their desired impacts, the more the "right" questions will flow. In this way, application of the framework is anticipated to enhance coaches' professional judgment during the coaching conversation, potentially increasing their confidence, competency, and presence in the moment. 


\section{References}

Brown, S. W., \& Grant, A. M. (2010). From GROW to GROUP: Theoretical issues and a practical model for group coaching in organisations.

Coaching: An International Journal of Theory, Research, and Practice, 3(1), 30-45.

Brunning, H. (2006). Executive coaching: systems-psychodynamic perspective. London, UK: Karnac.

Bushe, B. R., \& Marshak, R. J. (2009). Revisioning organization development. The Journal of Applied Behavioral Science, 45(3), 348-368.

Clutterbuck, D. (2007). Coaching the team at work. London, UK: Nicholas Brealey.

Cox, E. (2013). Coaching understood: A pragmatic inquiry into the coaching process. London, UK: Sage.

Glaser, B., \& Strauss, A. (1967). The discovery of grounded theory. London, UK: Aldine.

Gottlieb, J. Z. (1997). Understanding the role concept of organization development practitioners (Doctoral dissertation). Available from ProQuest Dissertations \& Theses database (UMI No. 9734283).

Gray, D. E. (2011). Journeys towards the professionalisation of coaching: Dilemmas, dialogues and decisions along the global pathway. Coaching: An International Journal of Theory, Research and Practice, 4(1), 4-19. https://doi.org/10.1080/17521882.2010.550896

Hackman, J. R., \& Wageman, R. (2005). A theory of team coaching. Academy of Management Review, 30(2), 269-287.

Hamlin, R., G., Ellinger, A. D., \& Beattie, R. (2007). Toward a professions of coaching? A definitional examination of 'coaching,' 'organization development,' and 'human resource development'. International Journal of Evidence Based Coaching and Mentoring, 7(1), 13 -38.

Hauser, L. (2014). Shape-Shifting: A team coaching model for coach practitioners, educators, and researchers. Journal of Psychological Issues in Organizational Culture, 5(2), 48-71.

Hornstrup, P., Madsen, J., \& Johansen, J. (2012). Developing relational leadership. Chagrin Falls, OH: Taos Institute.

Huffington, C. (2007). A contextualized approach to coaching. In H. Brunning (Ed.), Executive coaching: Systems-psychodynamic perspective. London, UK: Karnac.

ICF. (2017). Core competencies. International Coach Federation. Retrieved from 
https://www.coachfederation.org/credential/landing.cfm?ItemNumber=2 206\&navItemNumber $=576$

Ives, Y. (2008). What is 'coaching'?: An exploration of conflicting paradigms. International Journal of Evidence Based Coaching and Mentoring 6(2), 100-113.

Lippitt, G., \& Lippitt, R. (1986). The consulting process in action (2nd ed.). San Francisco, CA: Jossey-Bass/Pfeiffer.

Maltbia, T., Marsick, V., \& Ghosh, R. (2014). Executive and organizational coaching: A review of insights drawn from literature to inform HRD practice. Advances in Developing Human Resources, 16(2), 161-183. https://doi.org/10.1177/1523422313520474

Marshak, R. J., \& Grant, D. (2008). Organizational discourse and new organization development practices. British Journal of Management, 19, S7-S19.

Murphy, T. P. (2006). Judgment: The foundation of professional success.

Consulting Psychology Journal: Practice and Research, 58(4), 185-194.

Rogers, J. (2016). Coaching skills: A handbook. New York, NY: Open University Press.

Ruane, S. G. (2013). Coaching the self: Identity work(ing) and the selfemployed professional (Doctoral dissertation). Available from ProQuest Dissertations \& Theses database (UMI No. 3556281)

Stein, I. (2008). Enacting the role of coach: Discursive identities in professional coaching discourse (Doctoral dissertation). Available from ProQuest Dissertations \& Theses database (UMI No. 3306692)

Tomm, K. (1987). Interventive interviewing: I. Strategizing as a fourth guideline for the therapist. Family Process, 26(1), 3-13.

Tomm, K. (1988). Interventive interviewing: III. Intending to ask lineal, circular, strategic, or reflexive questions. Family Process, 27(1), 1-15.

WABC. (2017). Business coaching competencies. Retrieved from http://www.wabccoaches.com/includes/popups/competencies.html

\section{Author Contact}

Laura L. Hauser, $\mathrm{PhD}$

Greater Los Angeles area

www.linkedin.com/in/laurahauser5

laura@leadership-strategies.com 